\title{
Previous chronic cerebral infarction is predictive for new cerebral ischemia after carotid endarterectomy
}

\author{
Mehmet Besir Akpinar ${ }^{1 *}$, Veysel Sahin ${ }^{1}$, Neslin Sahin ${ }^{2}$, Ahmet Feyzi Abacilar ${ }^{1}$, Illker Kiris ${ }^{1}$, Ihsan Sami Uyar ${ }^{1}$ \\ and Faik Fevzi Okur ${ }^{1}$
}

\begin{abstract}
Background: The purpose of this study was to investigate the relation between preoperative chronic cerebral ischemia and postoperative new cerebral ischemia in patients undergoing carotid endarterectomy (CEA).

Methods: We reviewed the diffusion weighted magnetic resonance images (DWI) of the 51 patients (37 men, mean age $68.8 \pm 8.4$ years) undergoing isolated CEA in the preoperative and early postoperative period. The number, anatomic location and the size of new ischemic lesions were recorded.

Results: In the preoperative period, 28 (54.9\%) patients were symptomatic. There was chronic cerebral infarction in the preoperative DWI images of 17 patients (33.3\%). In the postoperative period, there was newly developed cerebral ischemia in postoperative DWI images of eight (15.7\%) patients. Six of the eight patients with newly developed cerebral ischemia had chronic cerebral infarction in their preoperative DWI images. The incidence of newly developed cerebral ischemia after CEA in patients with preoperative chronic cerebral ischemia was significantly higher than the incidence in patients without preoperative chronic cerebral ischemia $(p=0.01)$.
\end{abstract}

Conclusion: The results of the present study suggest that preoperative chronic cerebral ischemia may aggravate postoperative newly developed cerebral ischemia in patients undergoing CEA.

Keywords: Stroke, Carotid endarterectomy, Silent cerebral ischemia, Chronic cerebral ischemia, Transient ischemic attack

\section{Background}

Carotid Endarterectomy (CEA), first described in 1954 by Eastcott et al. [1], is a worldwide common procedure for the surgical treatment of carotid artery stenosis. The main objective of the CEA is to prevent or at least reduce the risk of future stroke. In concordance with this objective, well-accepted studies have documented that CEA ensured significantly better clinical outcome than medical therapy alone in both symptomatic and asymptomatic patients with $>70 \%$ carotid artery stenosis [2-5].

However, the surgery to prevent stroke itself carries a risk of stroke. Most perioperative neurological complications are ischemic complications caused by hemodynamic hypoperfusion and emboli released from fragile plaque

\footnotetext{
* Correspondence: mbakpinar@hotmail.com

'Department of Cardiovascular Surgery, Sifa University Faculty of Medicine,

Fevzipasa Bulvari No: 172/2 Basmane Konak, 35240 Izmir, Turkey

Full list of author information is available at the end of the article
}

during the arterial dissection and shunting, cross-clamping and declamping period [6]. These perioperative neurological events can develop during or early after CEA both in symptomatic or asymptomatic patients. Many patients manifest silent cerebral ischemia without any clinical sign that only can be diagnosed with diffusion weighted magnetic resonance (DWI) [7-9]. DWI is one of the most sensitive tool to evaluate newly developed cerebral ischemia after CEA [10, 11].

Although mechanisms and accompanying factors during perioperative neurological complications have been intensely investigated, the relation between preoperative chronic cerebral ischemia and development of postoperative cerebral ischemia remains unclear. The purpose of the present study was to investigate the relation between preoperative chronic cerebral ischemia and postoperative newly developed cerebral ischemia in patients undergoing CEA. For this purpose, we reviewed the DWI images of 
the 51 patients undergoing CEA in the preoperative and early postoperative period.

\section{Methods}

\section{Subjects}

Between October 2012 and February 2013, 51 patients (37 male, mean age $68.8 \pm 8.4$ ) who underwent CEA operation in our clinic were included into the study. $\mathrm{Pa}-$ tients with following conditions were not included in the study: non sinus cardiac rhythm, the presence of cardiac valvular disease, the presence of prosthesis inappropriate for MRI screening, history of cerebral operation, claustrophobia, disability and patients scheduled for concomitant open heart surgery.

Carotid artery stenosis was defined as symptomatic if ischemic stroke, transient ischemic attack (TIA) or retinal ischemia in the supply territory of the relevant carotid artery had occurred within the preceding 6 months [12]. The patients who did not have stroke, TIA or visual disturbance within the preceding 6 months were assumed as asymptomatic. Carotid artery stenosis was diagnosed by Duplex ultrasonography of carotid arteries in all patients. In case $60 \%$ or greater stenosis in common or internal carotid artery was obtained by Duplex ultrasonography, the patient was referred to carotid arteriography screening by conventional angiography or computerized tomography (CT) angiography, including arch and selectively both common carotids.

Demographics of the patients, atherosclerotic risk factors, status of contralateral carotid arteries, and the site of the CEA are summarized in Table 1. We used carotid Doppler ultrasonography (USG) for the preoperative screening of the patients undergoing coronary artery bypass graft (CABG) surgery. All of the asymptomatic cases were determined with this method.

The patients in the present study were without neurological disability and the time period between latest ischemic event and admission date was around 1 week.

Approval was obtained from the Clinical Research Ethics Committee of Sifa University (Sifa University Ethics Committee Clinical Trials Registration. date: 29.08.2012, number: B.30.2.SFU.00.50.500/49) and all subjects gave informed consent.

\section{Carotid artery ultrasound}

Carotid Doppler Ultrasound was used to evaluate the Carotid artery disease. (Sonoline Antares, Siemens Medical Solutions, Erlargen, Germany, 7.5-MHz linear-array transducers). A $\geq 70 \%$ ICA stenosis but less than near occlusion of the ICA is diagnosed when the ICA Peak Systolic Velocity (PSV) is greater than $230 \mathrm{~cm} / \mathrm{s}$ and visible plaque and luminal narrowing are seen at gray-scale and color Doppler US. Additional criteria include ICA/CCA PSV ratio $>4$ and ICA End Diastolic Velocity $(E D V)>100 \mathrm{~cm} / \mathrm{s}$. The higher the Doppler parameter lays above the threshold of $230 \mathrm{~cm} / \mathrm{s}$, the greater the likelihood of severe disease.

\section{Carotid arteriography}

The amount of stenosis was calculated as in the NASCET study: minimum residual lumen at the point of maximum stenosis referenced to the diameter of the distal lumen of the internal carotid artery at the first point at which the arterial walls became parallel. We offered CEA operation to patients with $\geq 60 \%$ ulcerated stenosis or $\geq 70$ stenosis in common or internal carotid stenosis obtained by arteriography.

\section{Magnetic resonance screening and evaluation}

MR imaging was performed using a 12-channel phased array head coil on a $1.5 \mathrm{~T}$ clinical scanner (Espree; Siemens, Erlangen, Germany). In addition to conventional MR sequences including fluid-attenuated inversion recovery (FLAIR), T1-weighted imaging and T2-weighted imaging, DWI and SWI sequences were also obtained. DWI was performed with a spin-echo-type EPI sequence: TR, $4200 \mathrm{~ms}$; TE, $114 \mathrm{~ms}$; b values of 0,500 and $1000 \mathrm{~s} / \mathrm{mm}^{2}$; FOV $230 \times 230 \mathrm{~mm}$; matrix size $256 \times 256$; section thickness, $5 \mathrm{~mm}$. The SWI consisted of a long TE (TR/TE 49/ $40 \mathrm{~ms}$, flip angle $20^{\circ}$ ) fully flow-compensated 3D FLASH sequence with a slice thickness of $2 \mathrm{~mm}$, FOV $230 \times$ $230 \mathrm{~mm}$, and matrix size $320 \times 320$.

MR imaging with DWI and SWI was prospectively performed a day before and in the time period between 24 and $48 \mathrm{~h}$ after CEA. MRI sequences were used to detect any ischemic lesions before and after CEA. On DWI, any new hyperintense area - regardless of size - the brain tissue was considered a sign of new ischemic lesions; on SWI, new hypointense signal intensity changes were interpreted as a sign of acute hemorrhage.

High signal intensity on T2-weighted and low signal intensity on T1-weighted images without diffusion restriction at one or more vascular territories or at border-zones were defined as 'chronic ischemia'. CEA timing for the symptomatic patients was one week after the occurrence of last symptom. The definition of 'chronic ischemia' has been done based on features of DWI images. Therefore, timing of the symptoms such as stroke or TIA had not been taken into consideration during this definition.

The number, anatomic location and the size of ischemic and hemorrhagic lesions were recorded. All the images were evaluated by an experienced radiologist (NS).

\section{Operative procedure}

All of the patients were operated on under general anesthesia. Systolic blood pressure was maintained at $140-150 \mathrm{mmHg}$ during carotid clamping. Eight mg of dexamethasone was administered before the application and after the removal of the cross clamp. 
Table 1 Baseline characteristics of the patients

\begin{tabular}{|c|c|c|c|}
\hline Characteristics & Asymptomatic patients $(n=23)(\%)$ & Symptomatic patients $(n=28)(\%)$ & Sum $(n=51)(\%)$ \\
\hline \multicolumn{4}{|l|}{ Demographics } \\
\hline Age, years & $68 \pm 9.4$ & $69 \pm 7.6$ & $68 \pm 8.2$ \\
\hline Male & $18(78.3 \%)$ & 19 (67.9\%) & 37 (72.5 \%) \\
\hline Female & $5(21.7 \%)$ & $9(32.1 \%)$ & $14(27.5 \%)$ \\
\hline \multicolumn{4}{|l|}{ Site of the CEA } \\
\hline Right & $12(52.2 \%)$ & $14(50 \%)$ & $26(51 \%)$ \\
\hline Left & $11(47.8 \%)$ & $14(50 \%)$ & $25(49 \%)$ \\
\hline \multicolumn{4}{|l|}{ Risk Factors } \\
\hline Hypertension & $13(56.5 \%)$ & $17(60.7 \%)$ & $30(58.8 \%)$ \\
\hline Diabetes Mellitus & $8(34.8 \%)$ & $12(42.8 \%)$ & $20(39.2 \%)$ \\
\hline Hyperlipidemia & $12(52.2 \%)$ & $15(53.6 \%)$ & $27(52.1 \%)$ \\
\hline Ischemic heart disease requiring $C A B G$ & $23(45.1 \%)$ & $2(3.9 \%)$ & $25(49.0 \%)$ \\
\hline \multicolumn{4}{|l|}{ Contra Lateral Carotid Artery Stenosis } \\
\hline$<50 \%$ & $17(73.9 \%)$ & 19 (67.9\%) & $36(70.6 \%)$ \\
\hline $50-70 \%$ & $4(17.4 \%)$ & $1(3.6 \%)$ & $5(9.8 \%)$ \\
\hline$\geq 70 \%$ & $2(8.7 \%)$ & $3(10.7 \%)$ & $5(9.8 \%)$ \\
\hline Total Occlusion & - & $5(17.8 \%)$ & $5(9.8 \%)$ \\
\hline \multicolumn{4}{|l|}{ Preoperative DWI Images } \\
\hline Acute ischemia & $3(14.3 \%)$ & 2 (7.1\%) & $5(10 \%)$ \\
\hline Chronic ischemia & - & 17 (60.7 \%) & 17 (33.3\%) \\
\hline \multicolumn{4}{|l|}{ Postoperative DWI Images } \\
\hline Acute ischemia & $2(8.7 \%)$ & $6(21.4 \%)$ & $8(15.7 \%)$ \\
\hline Acute hemorrhage & - & $1(3.6 \%)$ & $1(2 \%)$ \\
\hline
\end{tabular}

The numbers and the percentages of preoperative neurologic condition (symptomatic and asymptomatic cases) are summarized

The carotid arteries were explored through a longitudinal incision parallel to the medial aspect of the sternocleidomastoid muscle. The common, internal and external carotid arteries were explored. Following the intravenous administration of 200 unit $/ \mathrm{kg}$ heparin, CEA performed with eversion technique. The heparin was then reversed with protamine, and the patients were transferred to the intensive care unit, extubated and followed up.

Antiplatelet therapy was continued during the preoperative and postoperative period, and all of the patients were prescribed acetylsalicylic acid (150 mg oral/daily).

\section{Statistical analysis}

The demographic parameters of patients (gender, diabetes, hypertension, hyperlipidemia), the percentage of carotid stenosis, operative indication (symptomatic, asymptomatic) and the surgical sites (left, right) were evaluated. The preexisting ischemias in the DWI were determined. We examined whether all of these factors affected the development of new cerebral ischemia after CEA. Chi-squared Fisher Exact test was used for the statistical analysis. Statistical significance was set at a $P$-value $<0.05$.

\section{Results}

The mean age of the 51 studied patients was $68.8 \pm 8.4$ years (range 46-82). There were 37 men (72.5 \%) and 14 women (27.5\%). Arterial hypertension (58.8 \%) and hyperlipidemia $(52.9 \%)$ were the most frequent risk factors, followed by diabetes mellitus (39.2\%). Of the 51 carotid artery stenosis cases, 28 (54.9\%) were symptomatic (15 with TIA or amaurosis fugax and 13 with stroke) and 23 (45.1\%) were asymptomatic preoperatively. Twenty-six (51\%) patients operated from the right carotid artery, while 25 (49 \%) were from the left. The contralateral internal carotid artery was occluded in 5 patients $(9.8 \%$ ) and over the $70 \%$ degree stenosis in $5(9.8 \%)$. All these data are summarized in Table 1. Evidence of coronary artery disease requiring CABG was present in 25 patients, and these cases were referred to coronary bypass surgery a few days after CEA. The mean operative time was $72 \pm 18 \mathrm{~min}$., and mean cross clamp time was $13.2 \pm 5.3 \mathrm{~min}$. In eight patients (15.7\%), new cerebral ischemia was detected in DWI images within 24-48 h after CEA.

On pre-operative DWI images, acute and chronic cerebral ischemia was observed in 5 and 17 cases, respectively (Table 1). 
On post-operative DWI images; new cerebral ischemia was observed in $8(15.7 \%)$ and a new hypointense signal (hemorrhage) in 1 (3.6\%) case. Six of the 8 patients with new cerebral ischemia were the patients that had chronic infarction in their pre-operative DWI images. Most of the identified changes of the new signals were on the same side as the operation, and also near the chronic ischemic area (Fig. 1). The patient which the hemorrhage detected was one of the pre-operative chronic ischemia cases, and this patient developed a 4-mm diameter hemorrhage in the same location of ischemia after CEA. The locations, diameters and volumes of the lesions are summarized in Table 2.

Chronic cerebral infarction was found in the preoperative DWI images of 17 patients (33.3\%). DWI images showed that 6 of these 17 patients (35.3\%) experienced new silent cerebral ischemia in the post-operative period (Table 2) (Fig. 2). On the other hand, in the patients without chronic cerebral infarction (n: 34), we discovered 2 new postoperative cerebral ischemia $(5.9 \%)$ in their DWI images. The incidence of newly developed cerebral ischemia after CEA in patients with preoperative chronic cerebral ischemia was significantly higher than the incidence in patients without preoperative chronic cerebral ischemia $(p=0.01)$. The statistical analysis of chronic cerebral ischemia and newly developed cerebral ischemia are shown in Table 3.

The mean cross clamp time was $12 \pm 3$ min in 8 patients in whom we determined new ischemia after CEA. There were no significant differences between the patients for

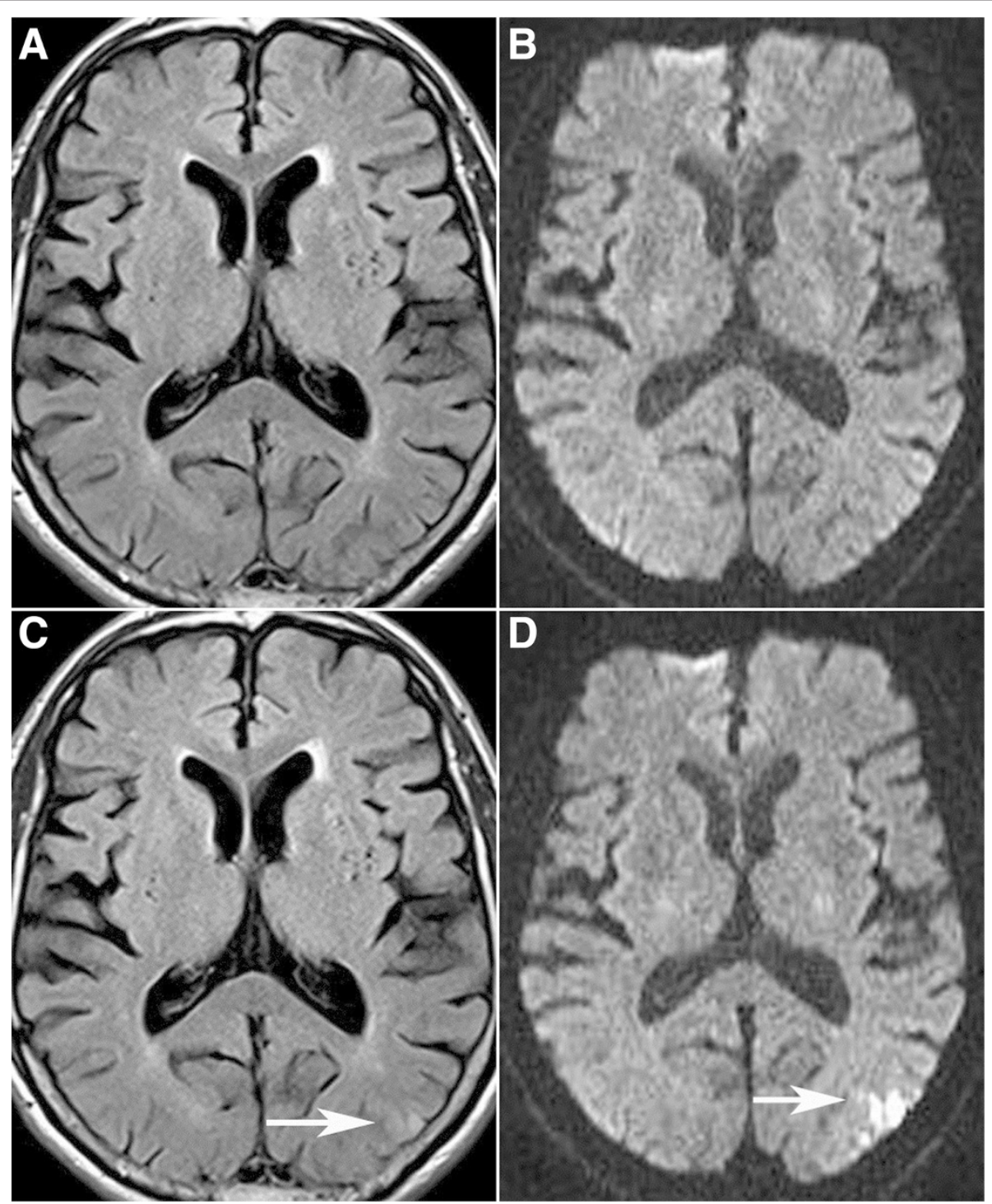

Fig. 1 Seventy-four-year-old man with 70 \% stenosis of left ICA. Preoperative (a) FLAIR and DWI (b) images show no abnormality. Postoperative FLAIR (c) and DWI (d) images demonstrate new left parietal small acute ischemic lesion (white arrow) which is not seen on preoperative images (a, b) 
Table 2 The size and location of postoperative DWI ischemic lesions, preoperative neurologic status and the level of contralateral carotid artery stenosis

\begin{tabular}{|c|c|c|c|c|c|}
\hline $\begin{array}{l}\text { Patients } \\
\text { (Names initials) }\end{array}$ & Preoperative symptoms & Site of the CEA & Pre operative DWI images & $\begin{array}{l}\text { New ischemic areas } \\
\text { on DWI }\left(\mathrm{cm}^{3}\right)\end{array}$ & $\begin{array}{l}\text { Contralateral carotid } \\
\text { artery stenosis (\%) }\end{array}$ \\
\hline ME & Asymptomatic & Left & Normal & Left occipital cortical $0.2 \mathrm{~cm}^{3}$ & 60 \\
\hline NY & Asymptomatic & Right & Normal & $\begin{array}{l}\text { Right parietooccipital } \\
\text { cortical } 0.55+0.06+0.26 \mathrm{~cm}^{3}\end{array}$ & 0 \\
\hline HB & $\mathrm{TIA}$ & Left & Left frontal chronic ischemia & Left frontal cortical $0.026 \mathrm{~cm}^{3}$ & 20 \\
\hline HD & TIA & Right & $\begin{array}{l}\text { Right occipital- right parietal } \\
\text { chronic ischemia }\end{array}$ & $\begin{array}{l}\text { Right posterior parietal } \\
\text { cortical } 0.016+0.022 \mathrm{~cm}^{3}\end{array}$ & 70 \\
\hline MB & $\mathrm{TIA}$ & Right & Right parietal chronic ischemia & Right frontoparietal $0.011 \mathrm{~cm}^{3}$ & 0 \\
\hline MA & Stroke & Right & Bilateral parietal chronic ischemia & $\begin{array}{l}\text { Right frontoparietal } \\
2.88+0.034 \mathrm{~cm}^{3}\end{array}$ & 70 \\
\hline NG & Stroke & Left & Left occipital chronic ischemia & Left occipital $0.04 \mathrm{~cm}^{3}$ & 0 \\
\hline HE & Stroke & Right & Left occipital chronic İschemia & Left parietooccipital $6.48 \mathrm{~cm}^{3}$ & 100 \\
\hline FB & $\mathrm{TIA}$ & Left & Left parietal chronic ischemia & Thalamic hemorrhage $0.025 \mathrm{~cm}^{3}$ & 0 \\
\hline
\end{tabular}

The last case on the list suffered cerebral hemorrhage

CEA Carotid endarterectomy, TIA Transient ischemic attack, DWI Diffusion-weighted MRI

new ischemia by cross clamp time, contralateral carotid artery stenosis rate, and demographical information $(p>0.05$, Table 3).

None of the patients experienced hematoma or infection on the operation area. We detected ipsilateral peripheral nerve damage (lingual deviation) in 1 patient.

One patient suffered ipsilateral hemiparesis for two hours after CEA. And this ischemic symptom disappeared after $6 \mathrm{~h}$ from CEA. The remaining new ischemias were silent cerebral ischemia.

\section{Discussion}

The results of the present study suggest that preoperative chronic cerebral ischemia may aggravate postoperative newly developed cerebral ischemia in patients undergoing CEA. The main finding of the study supporting this suggestion is the incidence of new cerebral ischemia in patients with preoperative chronic cerebral ischemia was significantly higher than the incidence in patients without preoperative chronic cerebral ischemia.

Cerebral infarction is a focal brain necrosis due to ischemia that affects all tissue elements of the brain. Most of the cerebral infarcts are caused by atherosclerosis of cerebral arteries, alone or with superimposed thrombosis. The risk factors for stroke include age, hypertension, diabetes mellitus, smoking, prior cardiovascular disease (coronary heart disease, cardiac failure or intermittent claudication), atrial fibrillation and left ventricular hypertrophy by
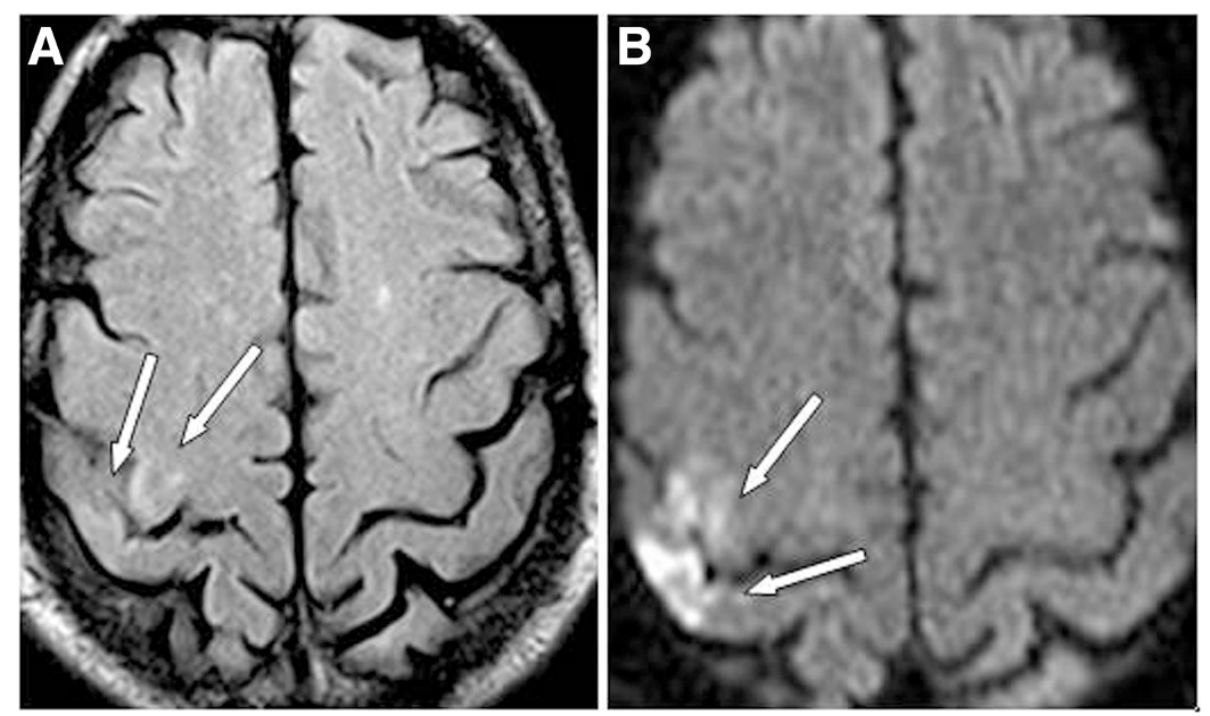

Fig. 2 Sixty-eight-year old man with $80 \%$ stenosis of right ICA. Preoperative DWI image shows right occipital chronic ischemia (a). Postoperative DWI image demonstrate new right parietooccipital ischemic lesion (b) (White arrows) 
Table 3 Statistical table of risk factors for new cerebral ischemia after carotid endarterectomy

\begin{tabular}{|c|c|c|c|}
\hline Characteristic & No. of patients & No. of patients with postoperative new ischemia & $P$-value \\
\hline \multicolumn{4}{|l|}{ Gender } \\
\hline Male & 37 & 6 & \\
\hline Female & 14 & 2 & 1.0 \\
\hline \multicolumn{4}{|l|}{ Hypertension } \\
\hline Yes & 30 & 5 & \\
\hline No & 21 & 3 & 1.0 \\
\hline \multicolumn{4}{|l|}{ Diabetes Mellitus } \\
\hline Yes & 20 & 3 & \\
\hline No & 31 & 5 & 1.0 \\
\hline \multicolumn{4}{|l|}{ Hyperlipidemia } \\
\hline Yes & 27 & 4 & \\
\hline No & 24 & 4 & 1.0 \\
\hline \multicolumn{4}{|c|}{ Contralateral Carotid Stenosis } \\
\hline Occlusion or $\geq 70 \%$ & 10 & 3 & \\
\hline Normal to moderate & 41 & 5 & 0.17 \\
\hline \multicolumn{4}{|c|}{ Preoperative neurologic status } \\
\hline Asymptomatic & 23 & 2 & \\
\hline Symptomatic & 28 & 6 & 0.26 \\
\hline \multicolumn{4}{|l|}{ The Site of the CEA } \\
\hline Right & 26 & 4 & \\
\hline Left & 25 & 3 & 1.0 \\
\hline \multicolumn{4}{|l|}{ Preoperative Brain Images } \\
\hline Chronic infarction & 17 & 6 & \\
\hline No chronic infarction & 34 & 2 & 0.01 \\
\hline
\end{tabular}

electrocardiogram [13]. The patients whom have 70-99\% stenosis in extracranial carotid arteries has 16.8-21.9\% risk of stroke rate per yearly [5]. Concordance with this report, we obtained previous cerebral ischemia in 22 of 51 patients in the preoperative period. The majority of the patients (17 of 22 patients) with previous cerebral ischemia had chronicle cerebral lesions.

DWI is used for detection of cerebral acute ischemia. DWI detects when $\mathrm{H}_{2} \mathrm{O}$ (hydrogen protons) are unable to diffuse freely. With cytotoxic edema, the $\mathrm{H}_{2} \mathrm{O}$ that normally surrounds the cells cannot diffuse as easily and becomes "restricted." DWI is very sensitive at detecting this change. Than the images of DWI becomes hyperintense (bright/positive) within minutes of acute ischemia $[14,15]$.

The symptoms and signs of TIA or stroke are indicators of cerebrovascular disease of the brain. The sensitivity rate of DWI for symptomatic cerebral ischemia is over $90 \%$ [16]. In our study, we used DWI as a sensitive diagnostic method to obtain acute cerebral ischemia. In addition, according to preoperative DWI images of the cases, we detected chronic cerebral ischemia in $60 \%$ of symptomatic patients. However, the results of neuropathological studies have shown that vascular disease manifesting as infarcts can result in injury to the brain in the absence of transient ischemic attack or stroke. These rates were determined 12-20 \% in Framingham and Rotterdam Scan Study studies, respectively $[17,18]$. In our study we did not detect any cerebral infarction in any asymptomatic case.

There are different surgical techniques for CEA including transvers or longitudinal arteriotomy, eversion or conventional techniques with carotid shunt usage [19]. It has been reported that eversion CEA has a lower restenosis rate than conventional CEA closure techniques and thus superior long-term durability. Today, eversion CEA is one of the most preferred technique with a postoperative stroke rate between 0.6 and $2.5 \%$ [20-22]. In this study all of the cases were operated with eversion CEA technique. Thus, we did not use carotid shunt for any patient due to the nature of the surgical technique.

Perioperative reduction of cerebral blood flow due to intraoperative clamping of the carotid artery and subsequent neuronal damage is reported to be the main cause of postoperative neurologic complications following CEA. 
Although its pathophysiology remains incompletely understood, micro emboli or subclinical micro infarcts are accused of being additional risk factors [23-25]. Vanmaele [26] noted a shorter cross-clamp time with eversion CEA. In our study, the mean carotid clamping time was also relatively short (13.2 $\pm 5.3 \mathrm{~min}$.) In addition, carotid cross clamping time of the patients with postoperative newly developed cerebral ischemia was not significantly different than of patients without cerebral ischemia.

In our study, there were contralateral carotid occlusion and severe (70 \% or higher) carotid artery stenosis in five and five patients, respectively. New cerebral ischemia developed in one patient with contralateral carotid occlusion and in two patients with contralateral severe carotid artery stenosis. Thus, we did not find a significant increment in the risk of development of new cerebral ischemia in patients with severe stenosis or occlusion in contralateral carotid artery stenosis.

Carotid artery disease is one of the etiological factors in the pathophysiology of post-CABG stroke [27]. Surgical management of the patients with coronary artery disease requiring $\mathrm{CABG}$ and carotid artery stenosis requiring CEA is still in debate. In our clinic, in patients with a stable coronary artery status, we prefer a staged procedure as first CEA-later CABG approach. In case critical proximal left anterior descending (LAD) or left main coronary artery stenosis exist, we prefer concomitant CABG and CEA operation. In the present study, the patients who underwent staged procedure but not concomitant procedure were included into the study.

There are different rates in the literature for the incidence of new or silence cerebral ischemia after CEA, including $0.2-15 \%[28,29]$. Silent brain infarctions are ischemic silent radiologic abnormalities that act as predictors of subsequent strokes and these lesions are associated with subtle deficits in physical and cognitive function that commonly go unnoticed [30,31]. The presence of silent infarcts more than doubles the risk of subsequent stroke and dementia [32].

In our clinique postoperative symptomatic stroke rate is under $2 \%$ after CEA [22]. In this study, we found 8 new ischemic images on DWI which 1 of them symptomatic (1.9\%), 7 of them asymptomatic -silence- ischemia $(13.7 \%)$ after CEA. According to the diameter of the ischemic areas, the largest one was $6.48 \mathrm{~cm}^{3}$ (24-mm diameter), while the remaining cases were smaller than $5 \mathrm{~mm}$ in diameter. The symptomatic patient experienced ipsilateral hemiparesis had $6.48 \mathrm{~cm}^{3}$ ischemia in parietooccipital region. We also identified 1 cerebral hemorrhage after CEA. In this case cerebral hemorrhage was at thalamic region.

The weakest sides of the artery capillary system of the brain are also the sides that are most sensitive for hypoperfusion. In these areas, the presence of "Watershedborder zone infarction' decreases perfusion pressure and increases the ischemia risk in the border zones [33]. The ischemic penumbra is described as the viable brain tissue adjacent to the area of ischemic infarction [34]. This area is more susceptible to ischemia than healthy brain tissue.

Incomplete and previous infarcts may also be the basis for silent brain ischemia. The effect of chronic cerebral infarctions on silent ischemia is not so clear. We couldn't find any literature about the effect of previous chronic cerebral infarctions on new cerebral ischemia development after CEA. It is thought that symptoms are absent because of the ischemic precondition [35].

In large series in the literature symptomatic carotid artery disease is accepted with an increased risk factor for stroke or death [36, 37]. Our study showed no significant difference in terms of the emerging cerebral ischemia in preoperative symptomatic and asymptomatic patients. All patients with chronic cerebral ischemia were symptomatic preoperatively. However, there was no chronic ischemia in all preoperative symptomatic cases. Accordingly, when defining the preoperative risk factors 'existence of chronic ischemic areas' may be an additional definition of risk for new-silent cerebral ischemia. Further studies are needed for this.

However, with a small sample size, caution must be applied when interpreting our results. All cases of new cerebral ischemia occurred in patients with previous chronic cerebral infarction and were also on the same side as the infarction. It can thus be suggested that chronic cerebral infarction makes the brain vulnerable to new ischemia.

In our patients, ischemia was similar to cortical and watershed infarcts that appeared on the sides of previous infarctions. In a case (one of the contralateral carotid occlusion cases) had chronic brain ischemia in occluded site on preoperative MRI image. In this case, postoperative DWI images showed new ischemic lesion on the contralateral (occluded) site, not on the operation site. This case also strengthened the idea that hypoperfusion is responsible for the ischemia. Therefore, especially in patients who have old infarcts, the brain is more susceptible to hypoperfusion. However, more research on this topic needs to be conducted.

\section{Conclusion}

In conclusion, the results of the present study suggest that preoperative chronic cerebral ischemia may aggravate postoperative newly developed cerebral ischemia in patients undergoing CEA. Regardless of whether they were symptomatic or not, the patients whose preoperative DWI images revealed chronic ischemia had much higher incidence of silent ischemia development after CEA than the patients who did not. Hence, it could conceivably be hypothesized that previous cerebral infarction was predictive for new silent cerebral ischemia after CEA. However, the mechanisms of cerebral ischemia are 
very complex and prospective clinical trials with large number of patients are needed to make more clear conclusions in the future.

\section{Abbreviations}

CEA: Carotid endarterectomy; DWl: Diffusion weighted magnetic resonance; SWI: Susceptibility weighted imaging; MRI: Magnetic resonance imaging; TIA: Transient ischemic attack; CT: Computerized tomography; USG: Doppler ultrasonography; CABG: Coronary artery bypass graft; ICA: Internal carotid artery; CCA: Common carotid artery; PSV: Peak systolic velocity; EDV: End diastolic velocity.

\section{Competing interests}

The authors declare that they have no competing interests.

\section{Authors' contributions}

MBA, FFO: Study concept and design. VS, AFA, ISU: Acquisition of data. NS: Analysis and interpretation of data. MBA, IK: Drafting and critical revision of manuscript. All authors read and approved the final manuscript.

\section{Acknowledgements}

This study funded by Sifa University education center.

\section{Author details}

${ }^{1}$ Department of Cardiovascular Surgery, Sifa University Faculty of Medicine, Fevzipasa Bulvari No: 172/2 Basmane Konak, 35240 Izmir, Turkey.

${ }^{2}$ Department of Radiology, Sifa University Faculty of Medicine, Izmir, Turkey.

Received: 3 June 2015 Accepted: 28 October 2015

Published online: 02 November 2015

\section{References}

1. Eastcott HH, Pickering GW, Rob CG. Reconstruction of internal carotid artery in a patient with intermittent attacks of hemiplegia. Lancet. 1954;264(6846):994-6.

2. Barnett H, Taylor W, Eliasziw M, Fox A, Ferguson G, Haynes RB, et al. Benefit of carotid endarterectomy in patients with symptomatic moderate or severe stenosis: North American Symptomatic Carotid Endarterectomy Trial collaborators. N Engl J Med. 1998;339(20):1415-25.

3. Walker MD, Marler JR, Goldstein M, Grady PA, Toole JF, Baker WH, et al. Endarterectomy for asymptomatic carotid stenosis. J Am Med Assoc 1995;273(18):1421-8

4. Halliday A, Mansfield A, Marro J, Peto C, Peto R, Potter J, et al. MRC Asymptomatic Carotid Surgery Trial prevention of disabling and fatal strokes by successful carotid endarterectomy in patients without recent neurological symptoms: randomized controlled trial. Lancet. 2004;363(9420):1491-502.

5. Biller J, Feinberg WM, Castaldo JE, Whittemore AD, Harbaugh RE, Dempsey RJ, et al. Guidelines for carotid endarterectomy. Circulation. 1998:97(5):501-9.

6. Huibers, D. Calvet, F. Kennedy, K.R. Czuriga-Kovács, R.L. Featherstone, F.L. Moll et al. Mechanism of Procedural Stroke Following Carotid Endarterectomy or Carotid Artery Stenting within the International Carotid Stenting Study (ICSS) Randomised Trial. http://dx.doi.org/10.1016/j.ejvs.2015.05.017.

7. Vermeer SE, Hollander M, van Dijk EJ, Hofman A, Koudstaal PJ, Breteler $M M B$, et al. Silent brain infarcts and white matter lesions increase stroke risk in the general population. Stroke. 2003;34:1126-9.

8. Jayasooriya G, Thapar A, Shalhoub J, Davies AH. Silent cerebral events in asymptomatic carotid stenosis. J Vasc Surg. 2011;54(1):227-36.

9. Schnaudigel S, Gröschel K, Pilgram SM, Kastrup A. New brain lesions after carotid stenting versus carotid endarterectomy: a systematic review of the literature. Stroke. 2008;39:1911-9.

10. Schaaf M, Mommertz G, Ludolph A, Geibprasert S, Mühlenbruch G, Das M, et al. Functional MR imaging in patients with carotid artery stenosis before and after revascularization. Am J Neuroradiol [Internet]. 2010;31(10):1791-8.

11. Das RR, Seshadri S, Beiser AS, Kelly-Hayes M, Au R, Himali JJ. Prevalence and correlates of silent cerebral infarcts in the Framingham offspring study. Stroke. 2008:39(11):2929-35.

12. den Hartog AG, Moll FL, van der Worp HB, Hoff RG, Kappelle LJ, de Borst GJ. Delay to endarterectomy in patients with symptomatic carotid artery stenosis. Eur J Vasc Endovasc Surg. 2014;47:233-9.

13. Wolf PA, D'Agostino RB, Belanger AJ, Kannel WB. Probability of stroke: a risk profile from the Framingham study. Stroke. 1991;22:312-8.
14. Schaefer PW, Grant PE, Gonzalez RG. Diffusion-weighted MR imaging of the brain. Radiology. 2000;217(2):331-45.

15. Fitzek C, Tintera J, Müller-Forell W, Urban P, Thömke F, Fitzek S, et al. Differentiation of recent and old cerebral infarcts by diffusion-weighted MRI. Neuroradiology. 1998;40(12):778-82.

16. Zuo L, Zhang Y, Xu X, Li Y, Bao H, Hao J, et al. A retrospective analysis of negative diffusion-weighted image results in patients with acute cerebral infarction. Sci Rep. 2015;17(5):8910.

17. DeCarli C, Massaro J, Harvey D, Hald J, Tullberg M, Au R, et al. Measures of brain morphology and infarction in the Framingham Heart Study: establishing what is normal. Neurobiol Aging. 2005;26:491-510.

18. Vermeer SE, Koudstaal PJ, Oudkerk M, Hofman A, Breteler MMB. Prevalence and risk factors of silent brain infarcts in the population based Rotterdam Scan study. Stroke. 2002;33:21-5.

19. Girn HRS, Dellagrammaticas D, Laughlan K, Gough MJ. Carotid endarterectomy: technical practices of surgeons participating in the GALA trial. Eur J Vasc Endovasc Surg. 2008;36:385-9.

20. Rockman CB, Halm EA, Wang JJ, Chassin MR, Tuhrim S, Formisano P, et al. Primary closure of the carotid artery is associated with poorer outcomes during carotid endarterectomy. J Vasc Surg. 2005;42(5):870-7.

21. Katras T, Baltazar U, Rush DS, Sutterfield WC, Harvill LM, Stanton PE. Durability of eversion carotid endarterectomy: comparison with primary closure and carotid patch angioplasty. J Vasc Surg. 2001;34(3):453-8.

22. Okur FF, Akpinar MB, Uyar IS, Sahin V, Abacilar AF, Maral J, et al. Experience of 352 carotid endarterectomy cases operated on without any shunt and a technical modification. Thirty-day results. Turkiye Klinikleri J Med Sci. 2013;33(5):1216-23.

23. Heyer EJ, Sharma R, Rampersad A, Winfree CJ, Mack WJ, Solomon RA, et al. A controlled prospective study of neuropsychological dysfunction following carotid endarterectomy. Arch Neurol. 2002;59:217-22.

24. Ghogawala Z, Westerveld M, Amin-Hanjani S. Cognitive outcomes after carotid revascularization: the role of cerebral emboli and hypoperfusion. Neurosurgery. 2008:62:385-95.

25. Gaunt ME, Martin PJ, Smith JL, Rimmer T, Cherryman G, Ratliff DA, et al. Clinical relevance of intraoperative embolization detected by transcranial Doppler ultrasonography during carotid endarterectomy: a prospective study of 100 patients. Br J Surg. 1994;81:1435-9.

26. Vanmaele RG, Van Schil PE, De Maeseneer MG, Meese G, Lehert P, Van Look RF, et al. Division-endarterectomy-anastomosis of the internal carotid artery: a prospective randomized comparative study. Cardiovasc Surg. 1994;2:573-81.

27. Naylor AR, Mehta Z, Rothwell PM, Bell PRF. Carotid artery disease and stroke during coronary artery bypass: a critical review of the literature. Eur J Vasc Endovasc Surg. 2002:23:283-94.

28. Roh HG, Byun HS, Ryoo JW, Na DG, Moon WJ, Lee BB, et al. Prospective analysis of cerebral infarction after carotid endarterectomy and carotid artery stent placement by using diffusion-weighted imaging. Ame J Neuroradiol. 2005;26(2):376-84.

29. Enevoldsen EM, Torfing T, Kjeldsen MJ, Nepper-Rasmussen J. Cerebral infarct following carotid endarterectomy: frequency, clinical and hemodynamic significance evaluated by MRI and TCD. Acta Neurol Scand. 1999;100:106-10.

30. Romero JR, Beiser A, Seshadri S, Benjamin EJ, Polak JF, Vasan RS, et al. Carotid artery atherosclerosis, MRI indices of brain ischemia, aging, and cognitive impairment: the Framingham study. Stroke. 2009:40(5):1590-6.

31. Vermeer SE, Prins ND, den Heijer T, Hofman A, Koudstaal PJ, Breteler MM. Silent brain infarcts and the risk of dementia and cognitive decline. N Engl J Med. 2003;348(13):1215-22.

32. Vermeer $\mathrm{S}$, Longstreth $\mathbf{W}$, Koudstaal P. Silent brain infarcts: a systematic review. Lancet Neurol. 2007;6(7):611-9.

33. Momjian-Mayor I, Baron JC. The pathophysiology of watershed infarction in internal carotid artery disease review of cerebral perfusion studies. Stroke. 2005;36:567-77.

34. Scalzo F, Nour M, Liebeskind DS. Data science of stroke imaging and enlightenment of the penumbra. Front Neurol. 2015;5(6):8.

35. Feng C, Bai $X, X u Y$, Hua T, Liu XY. The "silence" of silent brain infarctions may be related to chronic ischemic preconditioning and nonstrategic locations rather than to a small infarction size. Clinics (Sao Paulo). 2013;68(3):365-9.

36. Goodney PP, Likosky DS, Cronenwett JL. Factors associated with stroke or death after carotid endarterectomy in Northern New England. J Vasc Surg. 2008:48(5):1139-45.

37. Tu JV, Wang H, Bowyer B, Green L, Fang J, Kucey D. Risk factors for death or stroke after carotid endarterectomy observations from the ontario carotid endarterectomy registry. Stroke. 2003;34:2568-75. 